\title{
The Application Of Competency-Based Thinking in the Optimization Design of Higher Vocational Mathematics Teaching
}

\author{
Li Zhang ${ }^{1, a}$, Yanfen Guo ${ }^{2, b}$ \\ ${ }^{1}$ Foundation Department, Beijing Polytechnic College, Beijing, 100042,China \\ ${ }^{2}$ Foundation Department, Beijing Polytechnic College, Beijing, 100042,China \\ aemail:zhli929@126.com, bemail:w_guoguo@yahoo.com.cn
}

Keywords:Competency-based; higher vocational mathematics; optimization design; teaching refor

\begin{abstract}
Taking higher vocational mathematics teaching for an example, this paper describes the application of "competency-based" thinking in teaching design. Centering on the talent training goals of higher vocational education, the paper probes into the curriculum goals, optimization design and evaluation methods of higher vocational mathematics teaching, aiming at providing a reference for the reform of vocational mathematics teaching.
\end{abstract}

\section{Introduction}

In order to achieve sustainable development, higher vocational colleges must build the awareness of characteristic education and ensure the quality of teaching. Apart from the specialized courses, enough attention should also be paid to the general courses. Under such a circumstance, it is imperative to carry out the teaching reform of general courses. Higher vocational colleges must transform themselves into vocational activities-oriented, well-rounded education-based ones highlighting competency goals and putting students at the center of teaching. Competency-based education (called CBE for short), which originated from the United States and Canada, emphasizes making competency development the foundation of teaching and practicing strict scientific management and flexible teaching approaches. By shaking off the shackle of traditional teaching concepts and building upon the CBE theory, the new mathematics teaching method ensures that the goal of developing vocational competency can be smoothly attained.

\section{The Status QUO And Existing Problems In The Design Of Higher Vocational Mathematics Teaching}

In China's higher vocational colleges, mathematics is classified as a general course, therefore, it's teaching objects are ordinary senior high school and junior middle school students. In recent years, due to the shortage of prospective students in higher vocational colleges, the students' mathematical foundation is generally weak and they lack enthusiasm in learning mathematics, which resulted in widening difference between individual students. However, in terms of teaching design, the majority of teachers still follow the traditional teaching methods in which classes are dominated by knowledge inculcation from the teachers and the students' independent learning abilities are poor. In addition, the evaluation method is relatively single, with close-book examination as the main form. Because more attention is paid to summative evaluation rather than formulating a reasonable formative evaluation plan, the teaching quality is not effectively improved. At the same time, due to the teaching reform of higher vocational colleges, class hours of basic courses were cut down, including those of mathematics course. Therefore, in order to complete the teaching tasks, most of the teachers tend to adopt the cramming method of teaching, which is quite detrimental to the students' learning and digestion of knowledge. All in all, various factors dampened students' interest in mathematics learning and resulted in low teaching efficiency in higher vocational colleges. The best way to solve these problems is to integrate the student-centered thinking with the optimization design of curriculum, whereby the competency-based talent training 
goal can be gradually achieved.

\section{Curriculum Goals of Higher Vocational Mathematics Teaching Incorporating Competency-Based Thinking}

The National Outline for Medium-and-Long Term Educational Reform and Development puts forward that a modern vocational education system should be established by 2020 that adapts to the transformation of economic development mode, satisfy the requirements of the adjustment of industrial structure, embodies the concept of lifelong education and features the coordinated development of secondary and higher vocational education, so as to meet the people's needs of receiving vocational education as well as the economic and social needs for high-quality laborers and high-skilled talents. The curriculum goals of higher vocational mathematics teaching should be broken down into specific and operable actions in which knowledge objectives, competency objectives and affective objectives reinforce each other (see Figure 1 below).

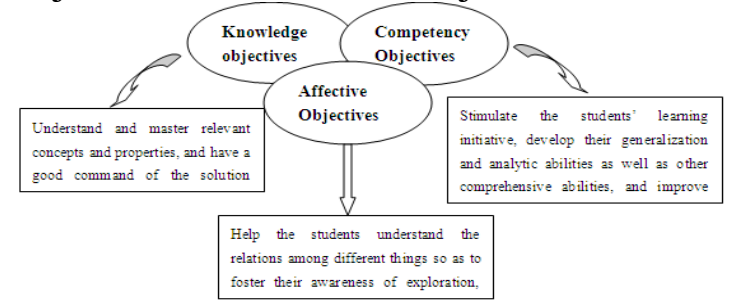

Fig. 1 Formulating curriculum goals

\section{The Compency-Based Optimization Design Of Higher Vocational Mathematics Teaching}

Competency-based education can be regarded as a management of the learning process, in which competency mainly refers to a kind of comprehensive ability containing three areas, namely, the relevant knowledge, the learning attitude and experience, and the feedback and evaluation on the learning result. As is shown in Figure 2 below, competency-based thinking is incorporated into the teaching design based on the classification and reconstruction of higher vocational mathematics courses.

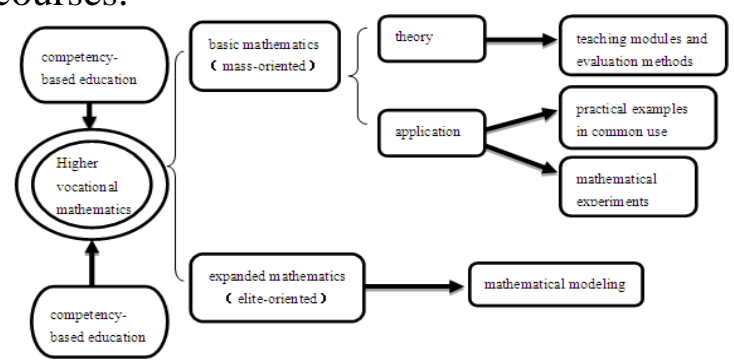

Fig. 2 The classification of higher vocational mathematics courses

1). Competency-oriented pure mathematics

Since theoretical knowledge is the foundation of applied mathematics and expanded mathematics, the teaching of pure mathematics still adhere to the traditional teaching thoughts. However, the traditional teaching activities are divided into multiple layers and modules in a step-by-step fashion so that the students would not be bored. The introduction of knowledge review sheet, learning task notice sheet and the sheet of new knowledge teaching and practicing enables the students to proactively obtain knowledge instead of passively accepting it. Although the design of pure mathematics teaching is still based on the traditional teaching thoughts, its main idea is to optimize the traditional teaching methods by dividing the whole process of teaching, learning and practicing into several stages so that the teaching methods become more procedural and systematic. What's more, the students develop their exploration and self-learning abilities in the course of pure mathematics study.

2). Applied mathematics focusing on practical application

Mathematical cases, basic mathematical experiments and mathematical modeling (taught from the easier to the more difficult) should be appropriately incorporated in the teaching of mathematics 
theories. In this way, the teachers will change their attitudes in preparing lessons, and the students' enthusiasm in learning will be greatly enhanced, their learning attitudes corrected and their independent learning abilities improved. In addition, more attention will be paid to the practical application and operation of basic mathematical knowledge so that the students can improve their analytic, reasoning and calculating abilities as well as the coordination, cooperation, organization, writing and expression abilities. This paper takes the design of new knowledge introduction sheet for an example, in which the guiding questions are listed in a table in accordance with the content of learning situations and sub-situations. All students are required to complete the tasks listed in the knowledge introduction sheet.

3). Interactive evaluation methods

Currently, traditional evaluation methods are still used in mathematics teaching in most higher vocational colleges, so that the students are tired of exams and they did poorly in those exams. Therefore, it is imperative to reform the evaluation methods. Since the talent training goal of higher vocational education is a competency-based, application-oriented one emphasizing innovation and improving the students' quality, the students' role as autonomous learners and the teachers' guiding role should be brought into full play and competency-based thinking can also be incorporated into the evaluation system of mathematics teaching.

Holding group leaders responsible for the formative evaluation.Enough importance should be attached to formative evaluation in higher vocational mathematics teaching, because it is an important way to improve the students' action and cognitive abilities. According to the actual situation, the students should be divided into groups and the group leaders should be selected by the teacher. The students can choose group members freely while the teachers will do some small adjustments in order to ensure the effectiveness of group learning. In this way, the group members will have a better environment for obtaining knowledge and the group leaders will also learn the knowledge by heart after repeated explanation. During the whole process, the teacher acts as the organizer and coordinator of the class. Prior to the final test that evaluates the learning result, the formative evaluation is conducted through self-evaluation and mutual evaluation among students. This evaluation method can help the students maintain their enthusiasm in learning, ensure that they have a thorough understanding of the knowledge they have learned, and enable students at various learning levels to make progress.

\section{Conclusion}

All in all, as an advanced educational thinking, competency-based education can be applied in the management of the learning process, as well as in the systematic development and planning of education, and it can certainly be used in the study of teaching models of different courses. By studying and integrating competency-based thinking into higher vocational mathematics teaching, this paper demonstrates that compared with the traditional teaching methods, competency-based education has clearer teaching goals, and it is better targeted and more operable. By integrating theoretical mathematics knowledge with the real application and operation, attaching more importance to learning than teaching, providing feedbacks in a timely manner, and giving objective evaluations on multiple dimensions, the new teaching methods can facilitate the sustainable development of the students, thus providing some guidance for the improvement of the teaching organization, management and design of mathematics courses.

\section{Acknowledgement}

In this paper, the research was sponsored by the Beijing Polytechnic College(Project No. bgzy2012jyjgxm13)

\section{References}

[1] Deng Junqian. Fundamentals of Applied Mathematics[M].Beijing: Huaxia Press,2005. 
[2] Zhou Yuxia. Exploration on the Curriculum Reform Guided by Competency-Based Curriculum Theory in Higher Vocational Colleges[J]. Human Resource Management, 2009(2).

[3] Liao Zheqin, Tian Huisheng. New Approach to Curriculum Theory[M]. Beijing: Educational Science Publishing House, 2003.

[4] Zhou Zhuo. A Study on the Optimization Design of Undergraduate Curriculum for Self-Taught English Majors Based on Competency-Based Education Theory[J]. Qingchunsuiyue, 2010 (12).

[5] Xu Lubo. Exploration on Incorporating People-First Philosophy into English Curriculum Design of Higher Vocational Colleges[J]. Xiangchao, 2009(3).

[6] Zhang Li. Research on Merging Action-Oriented Teaching Method into Mathematics Teaching in Higher Vocational Colleges[J].Journal of Beijing Polytechnic College, 2013 (1). 